\title{
Bankacılık Sektöründe Yoğunlaşma İle Finansal Kırılganlık Arasındaki İlişki: Türkiye Örneği (2007-2014)
}

\author{
Özge KORKMAZ * \\ Deniz ERER ${ }^{* *}$ \\ Elif ERER $^{* * *}$
}

\section{$\ddot{O Z Z E T}$}

Bankacılık sektöründe ortaya çıkan yoğunlaşmanın finansal kırılganlık üzerindeki etkisinin belirlenmesi ekonomi için oldukça önemlidir. Teoride bu ilişki "rekabet-istikrar" ve "rekabetkırılganlık" görüşleri çerçevesinde ele alınmaktadır. Bu çalışmada 2007:01-2014:09 dönemi için Türkiye örneği üzerinden hareketle, Türkiye'de faaliyet gösteren 19 banka için bankacıllk sektöründe ortaya çıkan finansal kirllganlı̆̆ etkileyen değişkenlerin tespit edilmesi, bu değişkenlerin kısa ve uzun dönemdeki etkilerinin ortaya konulması, yoğunlaşmanın finansal kırllganlık üzerindeki etkisinin belirlenmesi ve yoğunlaşma ile finansal kırılganlı arasındaki nedensel bağın varlığının araștırılması amaçlanmaktadir. Bu bağlamda Pearson Korelasyon matrisinden, Panel Klasik regresyon denklemlerinden ve Holtz-Eakin nedensellik analizinden faydalanılmıştır. Yapılan nedensellik analizi sonucunda, Türkiye için bankacılık sektöründe yoğunlaşma ile finansal kırılganlık arasında çift yönlü bir etkileşim olduğu tespit edilmiştir.

Anahtar Kelimeler: Yoğunlaşma, Finansal Kırılganlık, Bankacılık Sektörü, Panel Veri Analizi. JEL Sinıflandırması: D40, G210, C510, L22.

The Relationship Between Concentration And Financial Fragility In Banking Sector: The Case Of Turkey (2007-2014)

\section{ABSTRACT}

Determining of the effects of the concentration appearing in banking sector on financial fragility is extremely importance. In the theory, this relationship discusses within the frame of "competition-stability" and "competition-fragility". The aim of this study is to determine which variables financial fragility in banking sector affects, and to present short-run and long-run effects of these variables and the effect of concentration on financial fragility with reference to the example of Turkey over the period of 2007:01-2014:09. In this regard, it is taken advantage of Pearson correlation matrix, panel classical regression equations and Holtz-Eakin causality analysis. It is infered from the casuality analysis performed that there is two-way interaction between concentration and financial fragility in Turksih banking sector.

Keywords: Concentration, Financial Fragility, Banking Sector, Panel Data Analysis.

Jel Classification: D40, G210, C510, L22.

\footnotetext{
*Yrd.Doç.Dr. Özge Korkmaz, Bayburt Üniversitesi İktisadi ve İdari Bilimler Fakültesi İktisat Bölümü, ozgekorkmaz@gmail.com.

** Deniz Erer, Ege Üniversitesi, Sosyal Bilimler Enstitüsü İktisat Anabilim Dalı, denizerer@hotmail.com.

*** Elif Erer, Ege Üniversitesi Sosyal Bilimler Enstitüsü İktisat Anabilim Dalı, elif_erer_@hotmail.com.
} 


\section{GİRIŞ}

İstikrar kelimesi geçmişten günümüze değin önemli bir kavram olarak ele alınmaktadır. Özellikle de ekonomik istikrarın sağlanması birey, firma ve ülke bazında önemli bir yere sahiptir. $\mathrm{Bu}$ doğrultuda istikrarsızlığın ortaya çıkması istenilmeyen bir durumdur. Böyle bir durumda ise istikrarsızlığı ortaya çıkaran unsurlar belirlenmeye çalışılır. Finansal sistemin mevcut yapısı ve işleyiş mekanizması, istikrarsızlığın nedenleri hakkında öngörü yapılmasına olanak sağlamaktadır. Sistem içerisinde tanımlanmış piyasalar ile kurumların içsel yapısı ve bu yapılarda zaman içerisinde gerçekleşen dönüşümler, istikrarsızlık kaynaklarının belirlenmesinde ön plana çıkmaktadır (Bilgin, 2007: 19). Bir ekonomiyi, finansal istikrarsızlığa sürükleyen makro ve mikro etkenler söz konusudur. Genel olarak değerlendirildiğinde finansal istikrarsızlığı etkileyen faktörler finansal liberizasyon, sürdürülemez makro ekonomik politikalar, finansal yapının zayıf olması, politik istikrarsızlık, sermaye hareketlerindeki dalgalanmalar, teknolojik gelişim olarak sıralanabilir (Turgut, 2007: 39).

Bankalar, para ve kredi hizmetlerinin yerine getirilmesine yönelik faaliyette bulunan iktisadi birimlerdir. Bankalar, yeni bir servet yaratmayı, tasarrufların verimli ve karlı yatırım alanlarına akmasını ve ekonomik birimlere kaynak sağlaması nedeniyle ekonomiyi etkilemekte ve ekonomik kalkınmaya katkıda bulunmaktadır (Altay, 2014: 7). 1980 y1lından itibaren dünyada yaşanan teknolojik gelişme, finansal liberizasyon ve küreselleşme bankacılık sektöründe yoğun bir rekabetleşme ortamının oluşmasına neden olmuştur. Özellikle 2000 yılından sonra gerek Türkiye'de gerekse dünyada yaşanan ve ekonomide derin etkiler bırakan finansal krizler bankacılık sektörünün bir yapılanma sürecine girmesine neden olmuştur. Bankaların, fon aktarımında sahip olduğu aracılık fonksiyonu ve bu fonksiyonu ile firmaların büyümesinde, ekonomik refahın sağlanmasında ve sermaye birikimi üzerinde etkili olmaları bankacılık sektöründe yoğunlaşma ve rekabetin önem kazanmasını sağlamıştır (Ural, 2014: 397).

Bankacılık sektöründeki yoğunlaşmanın finansal istikrar üzerindeki etkileri konusunda farklı görüşler bulunmaktadır. "Rekabet-kırılganlık" görüşüne göre, bankacılıkta yoğunlaşmanın yüksek olduğu durumda bankalar riskli projeleri finanse etmekten kaçınmaktadırlar. Bu görüşe göre, banka rekabeti ve finansal istikrar arasında negatif bir ilişki vardır (Fernandez ve Garza-Garciag, 2012: 2). Bankacılık sisteminde daha az bir yoğunlaşma banka piyasa gücünü yıpratmakta, bu nedenle bankanın karlarının şimdiki değerini etkilemektedir (Allen ve Gale, 2004: 455). Diğer bir ifadeyle bankacılık sektöründe daha fazla rekabetin bankaların kar marjını azalttığı söylenebilmektedir (Berger ve diğerleri, 2009: 100). $\mathrm{Bu}$ durum, önceki kar düzeylerini devam ettirebilmeleri için, bankaların riskli politikalar izlemelerine neden olmaktadır. Sonuç olarak, daha riskli politikalar bankacılık sisteminde kırılganlık olasılığını arttırmaktadır. Bu nedenle, daha yoğunlaşmış bankacılık sistemi, daha yüksek kar elde etmeleri için bankaların daha güvenli stratejiler uygulamalarını teşvik etmektedir (Carletti ve Hartmann, 2002: 7-9). Boyd ve De Nicolo (2005) "rekabet-kırılganlık" 
modelinde banka rekabetinin borçlular üzerindeki etkilerinin göz ardı edildiğini, borçluların davranışını da dikkate aldıkları modellerden hareketle, rekabetin olmadığı bir durumun daha düşük düzeyde finansal istikrara neden olacağını ileri sürmüşlerdir. Bu görüş ise, literatürde "rekabet-istikrar" görüşü olarak adlandırılmaktadır. "Rekabet-istikrar" görüşü, bankacılıkta yoğunlaşmaya karşı çıkmakta ve sadece birkaç bankanın piyasa gücünün büyük bir kısmına sahip olmasının sonucu olarak kredi faiz oranlarının artacağını belirtmektedir (Cipollini ve Fiordelisi, 2009: 3). Daha yüksek faiz oranları, özellikle daha riskli projeleri üstlenen borçluların kredilerini geri ödemelerinde zorlanmalarına ve iflas etme olasılıklarının artmasına neden olmakta ve böyle bir durumun bankacılık sisteminin istikrarı üzerinde negatif bir etki yaratacağ1 belirtilmektedir (Stiglitz ve Weiss, 1981: 394). Bir diğer görüşe göre, banka rekabeti ve finansal istikrar arasında pozitif bir ilişki vardır (Fernandez ve GarzaGarciag, 2012, 2). Beck (2008), piyasa yapısı ve bankacılık sistem rekabetçiliği ile bankacılık sektör istikrarlığı arasındaki ilişkiyi incelemiş ve bankacılık sisteminde rekabet ve istikrar arasında pozitif bir ilişki olduğunu belirtmiştir. Bununla birlikte, liberizasyon ve serbest rekabetin kırılganlığa neden olmasının düzenleyici ve denetleyici başarısılıkların bir sonucu olduğunu ifade etmiştir.

$\mathrm{Bu}$ çalışmanın amac1, 2004:01-2014:09 dönemi için Türkiye için bankacılık sektöründe finansal kırılganlığı etkileyen faktörlerin belirlenmesinden ve kısa ve uzun dönem modellerinden hareketle belirlenen değişkenlerin finansal kırılganlık üzerindeki etkilerinin ortaya konulmasından oluşmaktadır. Ayrıca çalışmada, yoğunlaşma ile finansal istikrarsızlık arasındaki nedensel bağın varlığı araştırılmak istenmektedir.

\section{LITERATÜR}

Literatürde bankacılık sektöründe rekabet ve finansal istikrarı inceleyen çok sayıda çalışma mevcuttur. Bu çalışmalardan bazıları "rekabet-istikrar" görüşünü desteklerken, bazıları" rekabet-kırılganlık" görüşünün geçerli olduğunu ortaya koymaktadır. Bununla birlikte her iki görüşün geçerli olduğunu söyleyen çalışmalar da mevcuttur.

Keeley (1990), 1971-1986 döneminde Amerika'da 85 banka için rekabet-kırılganlık görüşünü test etmiştir. Çalışmada, varlıkların defter değeri, piyasa değeri/defter değeri, piyasa değeri/sermaye, defter değeri/sermaye,yabancı mevduatlar/toplam mevduatlar, nakit+hazine kağıtları/toplam varlıklar, New York Borsası bileşik endeksi, 3 aylık hazine bonosu faiz oranı, 20 yıllık hazine tahvili faiz oranı değişkenleri kullanılmış ve liberizasyon kukla değişken olarak ele alınmıştır. Çalışmada panel veri analizi aracılığıyla, rekabette meydana gelen artışın bankaların değerini azalttığı, aynı zamanda varlık riskindeki artış ve sermayedeki azalış nedeniyle bankaların temerrüt riskini artmasına neden olduğu sonuçlarına ulaşılmıştır. Hellmann ve diğerleri (2000) rekabet-kırılganlık ilişkisini genel denge modeli ile ele almışlar ve rekabetin bankaların ihtiyatlı davranış göstermelerini engellediğini ortaya koymuşlardır. Jimenez ve diğerleri (2007), 1988-2003 dönemi için İspanya bankacılık sisteminde piyasa yoğunlaşması-risk ilişkisini incelemek amacıyla geri ödenmeyen ticari krediler, rekabet, 
GSYIH, aktif karlıık, banka hacmi, kredi oranı değişkenlerini kullanılmışlardır. Çalışmada rekabet HHI endeksi ve Lerner endeksi olmak üzere iki açıdan ele alınmıştır.Analiz sonucunda, piyasadaki yoğunlaşmanın bankacıllk risk ölçüsü olarak kullanılan geri ödenmeyen ticari kredileri etkilemediği görülmüştür. Bununla birlikte, bankaya özgü faiz oranlarına dayalı olarak oluşturulan Lerner endeksi kullanıldığında, piyasa gücü ve banka riski arasında negatif bir ilişki olduğu tespit edilmiştir. Bu çalışmalar "rekabet-kırılganlık" görüşünü destekler niteliktedir.

Claessens ve Laeven (2004), 1994-2001 döneminde 50 ülke için rekabet ve istikrar arasındaki ilişkiyi panel veri analiziyle incelemişler ve rekabet ölçütü için Panzar-Rosse istatistiği kullanılmışlardır. Analiz sonucunda rekabette meydana gelen artışın finansal istikrarı arttırdığı tespit edilmiştir. Boyd ve Nicola (2005) "rekabet-istikrar" görüşünü genel denge modeli ile incelemişler ve piyasa gücünün artmasının bankacılık riskini de arttırdığ 1 ve daha yüksek faiz oranlarının ters seçim problemine yol açarak borçluların kredilerini geri ödemekte zorlanmalarına neden olduğu sonucuna ulaşmışlardır. Schaeck ve diğerleri (2006), 1980-2003 döneminde 38 ülke için "rekabet-kırılganlık" görüşünü panel logit model yöntemiyle inceledikleri çalışmada, rekabet ölçütü olarak Panzar Rosse $\mathrm{H}$ istatistiğini kullanmışlardır. Çalışmada aynı zamanda reel GSYİH büyümesi, reel faiz oranı, enflasyon, dış ticaret, ahlaki tehlike endeksi, M2/uluslararası rezervler, yoğunlaşma, İngiliz bankalarını gösteren kukla değişken, Fransız bankalarını gösteren kukla değişken, Alman bankalarını gösteren kukla değişken, faaliyet sınılamalarını gösteren kukla değişken, yabancı banka sahipliğini gösteren kukla değişken, kamu banka sahipliğini gösteren kukla değişken ve reel kredi büyümesi değişkenleri kullanılmıştır. Çalışma sonucunda, daha rekabetçi bir bankacılık sisteminin daha az sistematik krize eğilimli olduğunu ortaya koymuşlardır.Beck, DemirgüçKunt ve Levine (2006), 1980-1997 döneminde rekabet ve istikrar arasındaki ilişkiyi 69 ülke için panel logit yöntemiyle ele almışlardır. Bu amaçla ekonomik büyüme oranı, dış ticaret oranı, enflasyon oranı, kısa dönem reel faiz oranı, döviz kuru, M2/rezervler, kredi büyümesi, yoğunlaşma, bankacılık sektör bağımsızlığı, ahlaki tehlike, sermaye düzenleme endeksi, kamu bankaları, yabancı sermayeli bankalar, resmi denetleyici güç değişkenlerini kullanmışlardır. Çalışmada kırılganlık göstergesi olarak ise sistematik bankacılık krizleri göz önüne alınmıştır. Çalışma sonucunda rekabet ve istikrar arasında pozitif bir ilişki olduğu tespit edilmiştir. Boyd ve diğerleri (2006), 2003 y1lında 2500 Amerikan bankası ve 1993-2004 dönemi için 134 endüstrileşmemiş ülkedeki 2600 banka için yoğunlaşma ve istikrar arasındaki ilişkiyi genelleştirilmiş momentler yöntemi (GMM) ile ele almışlardır. Bu amaça $Z$ endeksi, toplam krediler/toplam varlıklar, aktife göre getiri, özkaynağa göre getiri, ortalama net gelir, HHI endeksi, varlıklar, işgücündeki büyüme, işsizlik oranı, tarımsal nüfus/toplam nüfus, medyan gelir değişkenleri kullanılmıştır. Analiz sonucunda artan rekabetin finansal istikrarı da arttırdığı gözlenmiştir. Bu çalışmalar ise, "rekabet-istikrar" görüşünü desteklemektedir.

Berger ve diğerleri (2009), 1999-2005 döneminde 23 gelişmiş ülke için kredi riski, banka riski ve banka öz sermayesi ile piyasa gücü arasındaki ilişkiyi GMM yöntemiyle 
incelemişlerdir. Çalışmada istikrar Z endeski ile, kırılganlık ise geri ödenmeyen krediler ile ölçülmüştür. Açıklayıcı değişkenler olarak Lerner endeksi, Herfindahl Hirschman Endeksi (HHI), HHI kredi endeksi, banka hacmi (toplam varlıklar), krediler/toplam varlıklar, sabit varlıklar/toplam varlıklar, kişi başına düşen GSYİH, yabancı banka sahipliği, kamu bankaların yüzdesi, bankacılık özgürlük endeksi kullanılmıştır. Çalışmada daha yüksek piyasa gücüne sahip olan bankaların daha düşük riske sahip olduğu sonucuna ulaşılmıştır. Dolayısı ile bu sonuç "rekabet-kırılganlık" görüşünün geçerli olduğuna işaret etmektedir. Aynı zamanda bu sonuç, piyasa gücünün kredi portföy riskini arttırdığını söyleyen "rekabetistikrar" görüşünün geçerli olduğunu göstermektedir. Çalışmada kredi-portföy riskinin bir dereceye kadar öz sermaye oranları tarafından karşılandığı ifade edilmiştir.

Nicolo ve Lucchetta (2011) bankacılıkta rekabet ve istikrar ilişkisini genel denge modeli kullanarak ele almışlardır. Analiz ölçeğe göre sabit getiri ve artan getiri için iki kısıma ayrılmıştır. Çalışma sonucunda, ölçeğe göre sabit getiri olması durumunda, bankacıllık sektöründe rekabetteki artışın aynı yönde riski etkilediği gözlenmiştir. Ölçeğe göre artan getiri var ise, rekabet ile risk arasında negatif bir ilişki ortaya çıktığı tespit edilmiştir. Sabit getiri durumunda "rekabet-kırılganlık" görüşü, artan getiri durumunda "rekabet-istikrar" görüşü geçerli olduğu sonucuna ulaşılmıştır.

Fernandez ve diğerleri (2012) 2001-2008 dönemi için Meksika bankacılık sektöründe rekabet-istikrar ilişkisini GMM yöntemi aracılığıyla incelemişlerdir. Çalışmada rekabet ilişkisi Lerner endeksi, finansal istikrar ve banka portföy riskleri ise sırasıyla $Z$ endeksi ve geri ödenmeyen kredi oranı ile ölçülmüştür. Çalışmada, kullanılan değişkenler Lerner endeksi, yabancı sahipliğini gösteren kukla değişken, toplam kredilerin toplam aktiflere oranı ve toplam aktiflerdir. Çalışmada bankacılık rekabeti ile finansal istikrar arasında pozitif bir ilişki bulunmuştur. Bu sonuç "rekabet-istikrar” görüşünü desteklemektedir. Çalışmada, aynı zamanda bankacılık rekabeti ile banka portföy riski arasında da pozitif bir ilişki tespit edilmiştir. Bu bulgu ise "rekabet-kırılganlık” görüşünü desteklemektedir. Ayrıca, daha yüksek bir rekabetin sistem istikrarı üzerindeki etkisi banka portföy riskindeki artıştan daha büyük bir öneme sahip olduğu söylenebilmektedir.

Liu ve Mirzaei (2013) bankacılıktaki rekabetin çıktı ve yeni iş yaratma açısından banka dışı endüstriler üzerindeki yayılma etkilerini incelemişlerdir. Bu amaçla 1993-2007 dönemi için 48 gelişmiş ve gelişmekte olan ekonomi için 23 endrüstri ve 6000 bankaya ait firma hacmi, endüstri büyümesi, dışsal finansal bağımlılık, özel sektöre verilen yurt içi krediler/GSYİH, banka kredisi/GSYİH, borsa endeksi, borsa devir oranı, yoğunlaşma (HH indeksi, H-istatistiği, Lerner indeksi), Z indeksi, mülkiyet hakları veriler kullanılmıştır. Panel veri analizinin kullanıldığı çalışmada, banka piyasasının daha rekabetçi olarak yoğunlaştığ ekonomilerde endüstriyel çıktı büyümesinin daha yüksek olduğu sonucuna ulaşılmıştır. Aynı zamanda, rekabetin güçlü olmadığ 1 gelişmekte olan ülkelerde banka yoğunlaşmasının büyüme üzerinde pozitif bir etkisi olduğu tespit edilmiştir. Bankacılık sektöründeki finansal istikrarın büyüme üzerindeki etkileri ise bölgelere göre değişmektedir. Bu doğrultuda gelişmiş 
ekonomilerde bu etkinin daha güçlü olduğu ve gelişmekte olan ülkelerde daha yumuşak olduğu söylenebilmektedir.

Türkiye'de yapılan çalışmalar incelendiğinde "rekabet-istikrar" görüşünün geçerliliği konusunda fikir birliğinin olmadığı, bu ilişkinin ele alınan değişkenler açısından farklılık gösterdiği görülmektedir. Yayla (2007), 1995-2005 dönemi için Türk bankacilık sektöründe yoğunlaşma ve rekabet arasındaki ilişkiyi ele almıştır. Yoğunlaşma endeksi olarak HHI endeksinin kullanıldığı çalışmada, 1995-1999 dönemi için yoğunlaşmanın azladığı, 20002005 döneminde ise bir artıs trendine girdiği sonucuna ulaşılmıştır. Abbasoğlu ve diğerleri (2007) , 1995-2005 dönemi için yoğunlaşma-rekabet ilişkisini incelemişlerdir. Yoğunlaşma endeksi olarak Panzar ve Rosse's modeli, H istatistiği, HHI endeksi, CR yoğunlaşma endeksi kullanılmıştır. Çalışma sonucunda yoğunlaşma ve rekabet arasında anlamlı bir ilişki bulunamamıştır.Tunay (2009), 1988-2007 dönemi için Türk bankacılık sektöründe rekabetin kırılganlık üzerindeki etkisini panel logit modeli aracılı̆̆ıla araştırmıştır. "Rekabetkırılganlık" ilişkisi bankaların mülkiyet yapıları ve uzmanlık alanlarına göre ayrı olarak ele alınmıştır. Bu amaçla yoğunlaşma oranı, özel bankaların aktif toplamı/sektörün aktif toplamı, yabancı bankaların aktif toplamı/sektörün aktif toplamı, özkaynaklar/aktif toplam, likit aktifler/mevduat + mevduat dışı kaynaklar, interbank kredileri/toplam mevduatlar, yabancı bankaların şüpheli alacakları, yabancı bankaların açtıkları toplam krediler, interbank reel faiz oranı ve dolar kurunun yıllık değişimi değişkenleri kullanılmıştır. Kırılganlık ölçütü olarak ise hem sistematik banka krizleri hem de ödenmemiş kredilerin toplam kredilere oranı alınmıştır. Analiz sonucunda kırılganlı ve yoğunlaşma arasında pozitif bir ilişki olduğu görülmüştür. Kocabay (2009), Z endeksi, ödenmemiş kredi oranları, yoğunlaşma, özel mülkiyetli bankaları gösteren kukla değişken, kamu mülkiyetli bankaları gösteren kukla değişken, enflasyon oranı, bütçe açığı, reel mevduat faiz oranı, döviz kurundaki değiş̧im oranı, iç borç stoku faiz oranı değişkenleri kullanılarak "rekabet-istikrar" görüşü 1990-2008 dönemi için panel veri analiziyle araştırılmıştır. Çalışma sonucunda, $\mathrm{Z}$ istikrar ölçütü kullanıldığında konsantrasyon oranları ve $\mathrm{H}$ istatistiği rekabet ölçütleri için sirasıyla "rekabet-istikrar" ve "rekabetkırılganlık" görüşlerinin geçerli olduğu görülmüştür. Bununla birlikte, istikrar göstergesi olarak ödenmemiş kredi oranları kullanıldığında ise tam tersi sonuçlar elde edilmiştir. Sonuç olarak , "rekabet-istikrar" görüşünün ele alınan değişkenler ve modeller açısından farklılık gösterdiği söylenebilmektedir. Yaldız ve Bazzana (2010) 2001-2009 dönemi için Türk bankacıllk sektöründe piyasa gücünün kredi riski ve banka riski üzerindeki etkisini incelemişlerdir. Bu amaçla 30 bankaya ait $\mathrm{Z}$ istikrar endeksi, Lerner endeksi, (toplam gelirtoplam maliyet)/toplam gelir, ödenmemiş krediler/toplam krediler, toplam varlıklar, net kar/toplam varlıklar, toplam gelir/toplam harcamalar, hisse değeri/toplam varlıklar, sanayi üretim endeksi verileri kullanılmış ve dinamik panel veri analizi uygulanmıştır. Çalışma sonucunda Türk bankacıllk sektöründe "rekabet-istikrar" görüşünün geçerli olduğu görülmektedir. Emek (2013), 1990-2003 dönemi için rekabet ve istikrar arasındaki ilişkiyi veri zarflama yöntemiyle incelemiş̧ir. Çalışmada rekabet, Panzar-Rose istatistiği ile ölçülmüştür. Bu amaçla faiz geliri, personel giderleri/personel sayısı, faiz giderleri/toplam 
yabancı kaynaklar, faaliyet giderleri/toplam aktif, aktif toplamı, likit aktifler/toplam aktif, geri ödenmeyen krediler/toplam krediler değişkenleri kullanılmıştır. Çalışma sonucunda "rekabetistikrar" görüşünün geçerli olduğu görülmüştür. İskenderoğlu ve Tomak (2013) 2002-2012 dönemi için 15 özel ticari bankaya ait çeyreklik aktif karlılık, sermaye oranı, mevduat oranı, yoğunlaşma oranı, banka büyüklüğü ve sabit varlıklar/toplam varlıklar değişkenleri kullanılmıştır. Finansal istikrar göstergesi olarak Z endeksi ve NPLs endeksi hesaplanmıştır. Dinamik panel veri yönteminin uygulandığı çalışma sonucunda, yoğunlaşma ve rekabet arasında anlamlı bir ilişki bulunamamıştır. Taşkın (2014), 2003-2013 dönemi için "rekabetistikrar" ilişkisini VAR yöntemiyle ele almış ve çalışmada finansal sağlamlık endeksi oluşturulmuştur. Piyasadaki rekabet ise Panzar-Rosse modeli ile ölçülmüştür. Finansal istikrar endeksi oluşturulurken aktif kalitesi, likidite, kur riski, faiz riski, karlılık ve sermaye yeterlilliği değişkenleri kullanılmıştır. Yoğunlaşma ve yabancı bankaların oranı kontrol değişken olarak modele dahil edilmiştir. Analiz sonuçları, finansal istikrarın artması durumunda kısa ve uzun dönemde rekabetin azaldığını göstermektedir. Ayrıca rekabetin istikrar üzerinde etkili olmadığ 1 sonucuna ulaşılmıştır.

Literatürde finansal kırılganlığı etkileyen faktörleri belirlemek üzerine yapılmış çalışmalar da mevcuttur. Ahumada ve Budnevich (2002), 1990-1998 dönemi için Şili bankacılık sisteminde finansal kırılganlığı dinamik panel veri analizi aracılığıyla incelemişlerdir. Finansal kırılganlığ temsilen iki göstergeyi ele almıştır. Bunlar ödenmemiş krediler/toplam krediler ve interbank faiz oranıdır. Çalışmada sermaye+rezervler/toplam aktifler, yönetim harcamaları/toplam aktifler, likit aktifler+nakitler/toplam mevduat, operasyonel marj/toplam aktifler, büyüme oranı, interbank kredileri/toplam mevduatlar, reel kredi oranı reel döviz kuru değişkenleri açıklayıcı değişkenler olarak kullanılmıştır. Pesola (2005), 1983-2002 dönemi için Almanya, Belçika, İspanya, İngiltere, Yunanistan ve dört kuzey Avrupa ülkelerinde finansal kırılganlı̆̆ etkileyen faktörleri dinamik panel veri analizi ile incelemiştir. Finansal kırılganlık göstergesi olarak net kredi zararları/kredi rasyosunu kullanmıştır. Bağımsız değişkenler kredi stoku/GSYİH, GSYİH büyüme oranı, cari gelirbeklenen gelir, reel faiz oranı değişkenleri kullanılmıştır. Jones ve Krause (2006), 1983-2002 dönemi için Latin Amerika'da bankacılık krizinin nedenlerini ortaya koymaya çalışmışlardır. $\mathrm{Bu}$ amaçla panel logit yöntemini kullanmışlardır. Kullanılan açıklayıcı değişkenler ise yabancı bankaları gösteren kukla değişken, dönemsel kredi büyümesi, büyüme oranı, enflasyon, diş ticaret hacmi, reel faiz oranı ve dolar kurudur. Ural ve Balaylar (2007), 19872007 dönemi için finansal istikrarsızlık endeksi oluşturmuşlar ve böylece finansal istikrarsızlığı etkileyen etmenleri ortaya koymaya çalışmışlardır. Kredi riskini belirtmek için özel sektöre verilen kredilerin; kur riskini belirtmek için banka dış yükümlülüklerinin, faiz riskini belirtmek için banka menkul değerler cüzdanının, likidite riskini belirtmek için banka mevduatlarının standartlaştırılmış değerlerinin ortalaması kullanılmıştır. Demireli (2010), 2000-2009 dönemi için Türk bankacılık sektöründe finansal kırılganlığı Yinelenen Birikimli Kareler ve GARCH yöntemleriyle incelemiştir. Çalışma sonucunda gerek ulusal gerekse küresel nitelikteki siyasi ve ekonomik olayların bankacılık sektöründe kırılganlığı arttırdığ1 
görülmüştür. Singh (2010), 2000-2009 dönemi için Hindistan bankacılık sektöründe kırılganlık endeksi hesaplamış ve sıralı probit model yardımıyla bankacılık krizlerini öngörmeye çalışmıştır. Çalışmada finansal kırılganlığın belirleyenleri likidite, kredi ve faiz oranı riski olarak sınıflanmışıtr. Finansal kırılganlık endeksini hesaplamak için özel likidite oranı, yabancı para varlık ve yükümlülükleri, ticari bankaların net rezervleri, mevduatlardaki yıllık büyümenin ağırlıklandırılmış ortalaması, reel gıda dışı krediler (real non-food credits), reel yatırımlar değişkenleri kullanılmıştır. Bankacıllk krizlerini öngörmek amacıyla ise 91 günlük hazine bonosu faiz oranı, ağırlıklandırılmış ortalama vadesiz kredi oranı, M3 para arzı, rezerv para, yabancı döviz rezervleri, ihracat, ithalat, reel efektif döviz kuru, enflasyon, büyüme oranı, borsa endeksi, ticari sektöre verilen banka kredileri değiş̧enleri kullanılmıştır. Saraçoğlu ve Kaplan (2012) , 1998-2012 dönemi için Türk bankacılık sektöründe finansal kırılganlık endeksini makro ekonomik değişkenler kullanarak hesaplamış ve bu endeksten hareketle bankacıllı kriz olasılıklarını elde etmiştir. Degryse, Elahi ve Penas (2013), 19942008 dönemi için Asya, Avrupa, Latin Amerika ve Amerika'da bankacıllk sistem kırılganlığını belirleyen faktörleri ele almışlardır. Bu amaçla çok değiş̧kenli lojistik modelden yararlanmışlardır. Çalışmada mikro bazda alınan açıklayıcı değişkenler likidite, sermaye değeri, yoğunlaşma, banka faaliyetlerinin farklılaştırılması, yabancı bankalar, bankaların fonlama yapısıdır. Makro değişkenler olarak döviz kuru, faiz oranı, borsa oynaklı̆ğ kullanılmıştır. Barışık ve Demirel (2014) 2002-2011 dönemi için Türk bankacılık sektöründe finansal kırılganlık endeksi oluşturmuşlardır. Bu amaçla banka kredileri, banka döviz pozisyonu, bankacılık sektörü kaldıraç oranı, hazine bonosu CDS primi, banka mevduatları, yabancı para cinsinden yükümlülük değişkenleri kullanılmıştır. Çalışma sonucunda enflasyondaki düşüşün finansal kırılganlığı azalttığı, CDS primlerinin ve döviz kurlarının ise banka kırılganlığını arttırdı̆̆ı görülmüsştür.

\section{VERİ SETI VE MODELLER}

Son zamanlarda özel kesiminin borçlanma oranlarının artışı ile Türk bankacılık kesiminde finansal kırılganlığın yaşanabileceği düşüncesi ileri sürülmektedir. Bu bağlamda çalı̧̧mada, Türk bankacılık sektöründe finansal kırılganlı̆̆ı etkileyen unsurlar ve yoğunlaşmanın finansal kırılganlı üzerindeki etkisi ortaya konulmak istenmektedir. Bu amaçla bankacılık sektörüne ait değişkenler 2007:01-2014:09 dönemi için kullanılmıştır. Bankalara ait veriler Türkiye Bankalar Birliği internet sitesinden elde edilmiştir. Veri yetersizliği nedeniyle toplam 19 ticari mevduat bankası çalışmaya dâhil edilmiştir. Tablo 1'de analize dâhil edilen bankalar gösterilmektedir. 
Tablo 1: Çalışmada Kullanılan Bankaların Listesi

\begin{tabular}{|l|l|l|}
\hline Akbank & Finansbank & Garanti Bankası \\
\hline Alternatif Bank & HSBC & İş Bankası \\
\hline Anadolu Bank & İng Bank & Vakıflar Bankası \\
\hline Arap Bank & Şekerbank & Yapı Kredi Bankası \\
\hline Bank Mellat & Tekstil Bank & Halk Bank \\
\hline Citibank & Türk Ekonomi Bankası & \\
\hline Denizbank & Ziraat Bankası & \\
\hline
\end{tabular}

Çalışmada kullanılan değişkenlere ait bilgiler, Tablo 2'de gösterilmektedir:

Tablo 2: Çalışmada Kullanılan Değişkenler

\begin{tabular}{|c|c|c|}
\hline Değişkenler & Değişkenlerin Adı & Açıklaması \\
\hline FK & Kırılganlık & Takipteki Krediler / Toplam Krediler \\
\hline S2 & Sermaye Yeterliliği & Bankaya Ait Özkaynak/ Bankaya Ait Aktif Toplamı \\
\hline KR & Kar & Bankaya Ait Net Kar veya Zarar/ Bankaya ait Özkaynaklar \\
\hline LKT & Likidite Oranı & Bankaya Ait Aktif Toplamı/ Bankaya Ait Mevduatlar \\
\hline $\mathrm{HHI}$ & Yoğunlaşma endeksi ${ }^{1}$ & $\sum_{i=1}^{n} S_{i}^{2} ; S_{i}$, i.inci firmanın pazar payıdır \\
\hline FM & Faiz marj1 & Net Faiz Geliri / Aktif Toplamı \\
\hline
\end{tabular}

Çalışmada finansal kırılganlığı etkileyen faktörler belirlenmek istenmektedir. Bu amaçla, Pearson korelasyon matrislerinden hareketle, kısa ve uzun dönem modelleri araştırılacaktır. Çalışmada ele alınan kısa ve uzun dönem modelleri genel hatları ile şu şekildedir:

Model 1: $F K_{\text {it }}=f\left(F M_{i t}, S 2_{i t}, H H I_{i t}, K R_{i t}, L K T_{i t}\right)$

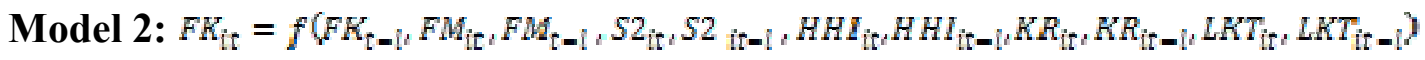

\footnotetext{
${ }^{1}$ Pazar yoğunlaşmasının ölçümünde Herfindahl-Hirschman Endeksi (HHI) yöntemi kullanılmaktadır. HHI indeksi birimler karşısında yoğunlaşmanın derecesini ölçerek bir değişkenin dağılımını karakterize etmektedir. HHI indeksindeki bir artış, rekabet dengesindeki azalışı göstermektedir (Owen ve diğerleri, 2005: 4).
} 
Çalışmada son olarak finansal kırılganlık ile yoğunlaşma arasındaki nedensel bağ araştırılmak istenmektedir.

\section{YÖNTEM}

Çalışmada "rekabet-istikrarsızlık" görüşü, statik model ve finansal kırılganlığın gecikmeli değerinin de bağımsız değişken olarak ele alındığı dinamik model aracılığıyla ortaya konulmak istenmektedir. Çalışmada Model 1 statik model, Model 2 dinamik modeldir. İlgili modellerin tahmin edilebilmesi için değişkenlerin birim kök içerip içermediğinin belirlenmesi gerekmektedir. Bir diğer ifadeyle değişkenlerin durağan olup olmadığ1 araştırılmalıdır. Panel veri analizinde birim kök testleri ise Birinci ve İkinci Nesil Birim Kök Testleri olmak üzere ikiye ayrılmaktadır. İlgili ayrım ise, çalışmada ele alınan modellerin yatay kesit bağımlılığı ile ilişkilidir. Dolayısı ile çalışmada ilk olarak modellerde yatay kesit bağımlılı̆̆ının var olup olmadı̆̆ı tespit edilmelidir.

Yatay kesit bağımlılı̆̆ının araştırılmasında, yatay kesit boyutunun zaman boyutundan küçük $(\mathrm{N}<\mathrm{T})$ olması durumunda Breusch Pagan (1980) tarafindan önerilen Breusch Pagan Lagrange Multiplier (LM) Yatay Kesit Bağımlılık Testi kullanılmaktadır. Breusch Pagan LM Yatay Kesit Bağımlılığı Testi'nde $\mathrm{H}_{0}$ hipotezi, "Yatay kesit denkleminin hata terimleri arasındaki korelasyon, sıfıra eşittir” şeklindedir ve LM istatistiği şu şekilde hesaplanmaktadır:

$$
C D_{L M}=T \sum_{i=1}^{N-1} \sum_{j=i+1}^{N} \hat{p} \hat{j}
$$

Burada $\hat{p}_{i j}$ hata terimlerinin ikili korelasyonlarına ilişkin örnek tahminidir (Hoyos ve Sarafidis, 2006: 485-486). $C D_{L M}$ istatistiğ $\mathrm{N}(\mathrm{N}-1) / 2$ serbestlik dereceli $x^{2}$ dağ 11 เmı göstermektedir ve $\mathrm{H}_{0}$ hipotezi reddedilmesi durumunda modelde yatay kesit bağımlılı̆ 1 olduğu söylenebilmektedir.

Yatay kesit bağımlılığının varlığı durumunda değişkenlerin durağanlığı İkinci Nesil Birim Kök Testleri aracılığıyla araştırılmaktadır. Literatürde en çok kullanılan İkinci Nesil Birim Kök Testleri'nden biri olan Pesaran Birim Kök Testi' dir ve şu şekilde hesaplanır:

$$
C I P S=\frac{1}{N} \sum_{i=1}^{N} C A D F_{i}
$$

CIPS istatistiği için kritik değerler çeşitli $\mathrm{N}$ ve $\mathrm{T}$ durumları için elde edilmektedir. $\mathrm{Bu}$ regresyona dayalı t testleri, $\Lambda_{i}^{\prime} f_{z}$ ve yatay kesit bağımlılı̆̆ını içermemektedir. Bu testlerin sınırlandırılmış dağılımı, gecikmeli düzeyin yatay kesit ortalaması nedeniyle Dickey-Fuller dağılımından farklılık göstermektedir (Baltagi, 2005:250). 
Panel veri analizinde değişkenler arasındaki nedensel bağ, Holtz-Eakin nedensellik analizi aracılığıla araştırılabilmektedir. Nedensellik analizine göre finansal kırılganlık ile yoğunlaşma arasındaki nedensel bağ için elde edilecek modeller ise şu şekildedir:

$$
\begin{aligned}
& F K_{i t}-F K_{i t-1}=\alpha_{0}+\sum_{j=1}^{m} \alpha_{j}\left(F K_{i t-j}-F K_{i t-j-1}\right)+\sum_{j=1}^{m} \delta_{j}\left(H H I_{i t-j}-H H I_{i t-j-1}\right)+\left(u_{i t}-u_{i t-1}\right) \\
& H H I_{i t}-H H I_{i t-1}=\alpha_{0}+\sum_{j=1}^{m} \alpha_{j}\left(H H I_{i t-j}-H H I_{i t-j-1}\right)+ \\
& \sum_{j=1}^{m} \delta_{j}\left(F K_{i t-j}-F K_{i t-j-1}\right)+\left(u_{i t}-u_{i t-1}\right)
\end{aligned}
$$

Burada j uygun gecikme sayısını ifade etmektedir.

\section{BULGULAR}

Çalışmada araştırılmak istenilen regresyon denklemlerinde sahte regresyon probleminden kaçınılmak amacıyla, ilk olarak serilerin birim kök içerip içermediği araştırılmalıdır. $\mathrm{Bu}$ doğrultuda çalışmada, değişkenlere ilişkin durağanlık analizine yer verilmek istenmektedir. Model 1 ve Model 2'de yer alan değişkenler için durağanlı̆̆ın araştırılmasından önce, modellerde yatay kesit bağımlılı̆ının var olup olmadığı belirlenmelidir. Dolayısı ile ilk olarak Model 1 ve Model 2 için yatay kesit bağımlılığının varlığı araştırılacaktır. Bu bağlamda yatay kesit bağımlılığını test etmek amacıyla Breusch

\begin{tabular}{|c|c|c|}
\hline & Model 1 & Model 2 \\
\hline LM İstatistik Değeri & 335.4485 & 269.0112 \\
\hline Olasılık Değeri & $0.0000^{* * *}$ & $0.0000^{* * *}$ \\
\hline
\end{tabular}
Pagan LM testi uygulanmış ve elde edilen sonuçlar ise Tablo 3’te gösterilmiştir.

Tablo 3: Breusch Pagan LM Yatay Kesit Bağımlılığı Testi

Tablo 3'teki sonuçlar incelendiğinde, yatay kesit bağımlılı̆̆ının olmadığını söyleyen sıfir hipotezi reddedilmektedir. Dolayısı ile Model 1 ve Model 2'de yatay kesit bağımlılığının var olduğu söylenebilmektedir. Breusch-Pagan LM yatay kesit bağımlılı̆̆ test sonuçlarından hareketle serilerin durağanlığı yatay kesit bağımlılığını dikkate alan İkinci Nesil Birim Kök Testleri'nden olan Pesaran CADF Testi aracılığıyla araştırılmıştır. Elde edilen birim kök test sonuçları ise, Tablo 4'te rapor edilmiştir. 
The Journal of Accounting and Finance

January/2016

Tablo 4: Pesaran Durağanlık Test Sonuçları (Düzey)

\begin{tabular}{|l|l|l|l|l|l|}
\hline \multicolumn{5}{|l|}{ Sabit Terimli } & \multicolumn{3}{l|}{ Sabit Terimli ve Trendli } \\
\hline Değişkenler & İstatistik Değeri & $\begin{array}{l}\text { Olasılık } \\
\text { Değeri }\end{array}$ & Değişkenler & İstatistik Değeri & Olasılık Değeri \\
\hline FK & $-1.725(1)$ & 0.582 & FK & $-2.316(1)$ & 0.548 \\
\hline S2 & $-1.511(1)$ & 0.886 & S2 & $-1.830(3)$ & 0.994 \\
\hline KR & $-3.115(1)$ & $0.000^{* * *}$ & KR & $-3.017(1)$ & $0.000^{* * *}$ \\
\hline LKT & $-1.723(1)$ & 0.585 & LKT & $-2.566(1)$ & 0.131 \\
\hline HHI & $-1.836(1)$ & 0.379 & HHI & $-2.335(1)$ & 0.511 \\
\hline FM & $-2.875(3)$ & $0.000^{* * *}$ & FM & $-2.550(3)$ & 0.149 \\
\hline $\begin{array}{l}\text { Uygun gecikme sayı1 Akaike bilgi kriterine göre belirlenmiştir. Parantez içerisindeki ifadeler, uygun gecikme sayısını } \\
\text { göstermektedir. }{ }^{* * *} \text { ve }{ }^{* * *} \text { sırasıyla } 0.10,0.05 \text { ve } 0.01 \text { düzeyinde istatistiksel olarak anlamlilığ ifade etmektedir. }\end{array}$ \\
\hline
\end{tabular}

Tablo 4 incelendiğinde, kar değişkeninin hem sabit terimli hem de sabit terimli ve trendli birim kök denklem sonuçlarına göre düzeyde durağan olduğu sonucuna ulaşılmıştır. Faiz marjı değişkeni için sabit terimli birim kök denklemi dikkate alındığında durağan olduğu söylenebilirken, sabit terimli ve trendli birim kök denklemi için durağan olmadığı sonucu tespit edilmiştir. İlgili değişkenin grafiğgi ele alındığında, değişkenin hem sabit terime hem de trende sahip olduğu gözlenmiş ve bu nedenle faiz marjı için sabit terimli ve trendli birim kök sonucunun dikkate alınması gerektiğine karar verilmiştir. Pesaran sabit terimli ve de sabit terimli ve trendli birim kök birim kök test sonuçları diğer tüm değişkenler için ele alındığında ise, kar değişkeni hariç tüm değişkenlerin durağan olmadiğ 1 tespit edilmiştir. $\mathrm{Bu}$ nedenle değişkenlerin durağanlığı birinci farkları için araştırılmış ve elde edilen sonuçlar Tablo 5 'te sunulmuştur.

Tablo 5: Pesaran Durağanlık Test Sonuçları (Birinci Fark)

\begin{tabular}{|c|c|c|c|c|c|}
\hline \multicolumn{3}{|l|}{ Sabit Terimli } & \multicolumn{3}{|c|}{ Sabit Terimli ve Trendli } \\
\hline Değişkenler & $\begin{array}{l}\text { İstatistik } \\
\text { Değeri }\end{array}$ & $\begin{array}{l}\text { Olasillk } \\
\text { Değeri }\end{array}$ & Değişkenler & $\begin{array}{l}\text { İstatistik } \\
\text { Değeri }\end{array}$ & $\begin{array}{l}\text { Olasılık } \\
\text { Değeri }\end{array}$ \\
\hline FK & $-8.610(1)$ & $0.000^{* * *}$ & FK & $-6.852(1)$ & $0.000^{* * *}$ \\
\hline S2 & $-8.535(1)$ & $0.000^{* * * *}$ & S2 & $-3.980(1)$ & $0.000^{* * *}$ \\
\hline KR & $-4.622(1)$ & $0.000^{* * * *}$ & $\mathrm{KR}$ & $-4.058(1)$ & $0.000^{* * *}$ \\
\hline LKT & $-4.376(1)$ & $0.000^{* * *}$ & LKT & $-3.115(1)$ & $0.000^{* * *}$ \\
\hline HHI & $-3.617(1)$ & $0.000^{* * *}$ & HHI & $-3.718(1)$ & $0.000^{* * *}$ \\
\hline FM & $-13.989(2)$ & $0.000^{* * *}$ & FM & $-2.947(3)$ & $0.001^{* * *}$ \\
\hline
\end{tabular}


Tablo 5 ele alındığında, durağan olmayan tüm değişkenlerin, birinci farklarında durağan olduğu sonucuna ulaşılmıştır. Çalışmanın bu kısmında değişkenler arasındaki ilişki araştırılmak istenmektedir. Değişkenlerin durağan olduğu seviye/farklar dikkate alınarak Pearson korelasyon matrisi aracılığıyla değişkenler arasındaki ilişki araştırılmış ve Tablo 6'da Pearson korelasyon matrisi sonuçları sunulmuştur.

Tablo 6:Pearson Korelasyon Matrisi

\begin{tabular}{|l|l|l|l|l|l|l|}
\hline & $\Delta \mathrm{FK}$ & $\Delta \mathrm{S} 2$ & $\mathrm{KR}$ & $\Delta \mathrm{LKT}$ & $\Delta \mathrm{HHI}$ & $\mathrm{FM}$ \\
\hline$\Delta \mathrm{FK}$ & 1.0000 & & & & & \\
\hline$\Delta \mathrm{S} 2$ & $0.1754^{* * *}$ & 1.0000 & & & & \\
\hline $\mathrm{KR}$ & -0.0048 & 0.0483 & 1.0000 & & & \\
\hline$\Delta \mathrm{LKT}$ & 0.0071 & $0.2930^{* * *}$ & -0.0189 & 1.0000 & & \\
\hline$\Delta \mathrm{HHI}$ & 0.0251 & 0.0227 & -0.0139 & -0.0128 & 1.0000 & \\
\hline \begin{tabular}{l} 
FM \\
\hline \multirow{7}{*}{$0.0712^{* *}$}
\end{tabular} & $0.1407^{* * *}$ & $0.4100^{* * *}$ & 0.0118 & 0.0348 & 1.0000 \\
\hline \\
etmektedir.
\end{tabular}

Tablo 6 ele alındığında finansal kırılganlık ile sermaye yeterliliği arasında, sermaye yeterliliği ile likidite oranı arasında, finansal kırılganlık ile faiz marjı arasında, faiz marjı ile sermaye yeterliliği arasında ve faiz marjı ile kar oranı arasında istatistiki olarak anlamlı ilişkiden bahsedilebilmektedir. Dolayısı ile finansal kırılganlı̆̆ı etkileyen değişkenler Pearson korelasyon matris sonuçlarından hareketle belirlenebilmiştir. Bu bağlamda kısa ve uzun dönem modelleri şu şekilde ifade edilebilinir:

Model 1: $F R_{\text {it }}=\beta_{0}+\beta_{1} F M_{i t}+\beta_{2} S 2_{i t}+\varepsilon_{i t}$

Model 2: $\quad F K_{i t}=\beta_{0}+\beta_{1} F K_{t-1}+\beta_{2} F M_{i t}+\beta_{3} F M_{z-1}+\beta_{4} S 2_{i t}+\beta_{5} S 2_{i t-1}+\varepsilon_{i t}$

Kısa ve uzun dönem modellerinin birim ve zaman etkilerinin varlı̆̆ına karar verebilmek adına $F$ ve Hausman testlerinden faydalanılmıştır. Bu doğrultuda çalışmada ele alınan modeller için ilgili test sonuçları Tablo 7'de gösterilmektedir.

Tablo 7: F Testi ve Hausman Test Sonuçları

\begin{tabular}{|c|c|c|c|c|}
\hline & \multicolumn{2}{|l|}{ F Testi } & \multicolumn{2}{|l|}{ Hausman Testi } \\
\hline & İstatistik Değeri & Olasılık Değeri & İstatistik Değeri & Olasılık Değeri \\
\hline Model 1 & 1.3949 & 0.9937 & 10.34 & $0.0054^{* * *}$ \\
\hline Model 2 & 6.0437 & 0.9960 & 2.728 & 0.9502 \\
\hline \multicolumn{5}{|c|}{$\begin{array}{l}\text { *** }^{* * *} \text { ve } \\
\text { etmektedir. }\end{array}$} \\
\hline
\end{tabular}


Tablo 7'de yer alan F testi sonucuna göre her iki model için de birim ve zaman etkilerinin önemsiz olduğunu söyleyen $\mathrm{H}_{0}$ hipotezi reddedilmemiştir. Dolayısı ile çalışmada ele alınan Model 1 ve Model 2 klasik regresyon modeli olarak tahmin edilmesine karar verilmiştir.

Çalışmada ilk olarak kısa dönem modeli olan Model 1 klasik regresyon modeli olarak tahmin edilmiştir. Modellerden elde edilen bilgilerin güvenilirliği ekonometrik varsayımların geçerliliğgi ile ilişskilidir. $\mathrm{Bu}$ amaçla Model 1 için temel varsayımların geçerliliği araştırılmıştır. Model 1'de otokorelasyon ${ }^{2}$ ve farklı varyans ${ }^{3}$ sorunu olduğu tespit edilmiştir. Model 1'den elde edilen bilgilerin tutarlı olabilmesi için model, farklı varyans sorununu ortadan kaldırılmasına imkan sağlayan dirençli standart hatalar yöntemi ile tahmin edilmiştir. Buna göre tahmin edilen Model 1 sonuçları, Tablo 8'de sunulmuştur.

Tablo 8: Model 1 Sonuçları

\begin{tabular}{|c|c|c|c|c|}
\hline \multicolumn{5}{|c|}{ Bağımlı Değisşen: $\Delta \mathrm{FK}_{\mathrm{t}}$} \\
\hline Değişkenler & Katsayı & Robust Standart Hata & t-İstatistiği & Olasılık Değeri \\
\hline Sabit terim & -0.0012 & 0.0019 & -0.62 & 0.535 \\
\hline$F M_{\mathrm{t}}$ & 0.0368 & 0.0309 & 1.19 & 0.233 \\
\hline$\Delta \mathrm{S} 2_{\mathrm{t}}$ & 0.2202 & 0.8482 & 2.60 & $0.099^{*}$ \\
\hline \multicolumn{3}{|c|}{$\mathrm{R}^{2}=0.6294$} & \multicolumn{2}{|c|}{$\gamma^{2}=7.96\left(0.0000^{* * *}\right)$} \\
\hline
\end{tabular}

Model 1 incelendiğinde sermaye yeterliliği oranının istatistiki olarak anlamlı olduğu faiz marjı oranının ise istatistiki olarak anlamlı olmadığı belirlenmiştir. Bu sonuçlardan hareketle, sermaye yeterliliğindeki bir artışın finansal kırılganlığı 0.2202 oranında artırdı̆̆ sonucuna ulaşılmıştır. Model 1'in açıklama gücü ele alındığında ise, bağımlı değişkende meydana gelen değişmelerin \%62.94'ünün bağımsız değişkenler tarafindan açıklandığı tespit edilmiştir.

Çalışmada uzun dönem modeli olan Model 2 de klasik regresyon modeli olarak tahmin edilmiştir. Daha önce belirtildiği gibi modelden elde edilen bilgilerin güvenilirliği için temel varsayımların geçerliliği araştırılmıştır. Model 2'de otokorelasyon sorunu olmadığ ${ }^{4}{ }^{\text {ancak }}$

\footnotetext{
${ }^{2}$ Wooldridge Otokorelasyon Testi'ne göre, istatistik değeri 44.599 ve 0.01 önem düzeyinde kritik değer 36.1908'dir. Kritik değer istatistik değerinden küçük olduğu için " $\mathrm{H}_{0}$ : Modelde otokorelasyon yoktur" hipotezi reddedilmiştir.

${ }^{3}$ White Farklı Varyans Testi'ne göre istatistik değeri 923.98 ve 0.01 önem düzeyinde kritik değer 9.21034'dür. Kritik değer istatistik değerinden büyük olduğu için " $\mathrm{H}_{0}$ : Modelde farklı varyans sorunu yoktur" ifadesi reddedilmiştir.

${ }^{4}$ Wooldridge Otokorelasyon Testi'ne göre, Model 2'nin istatistik değeri 1.177'dir. 0.01 önem düzeyinde kritik değer 36.1908'dür. Kritik değer, istatistik değerinden büyük olduğu için " $\mathrm{H}_{0}$ : Modelde otokorelasyon yoktur" hipotezi reddedilememiştir.
} 
modelde farklı varyans sorunu olduğu ${ }^{5}$ tespit edilmiştir. Bu bulgulardan hareketle Model 2, dirençli standart hatalar yöntemi aracılığıyla tahmin edilmiş ve elde edilen sonuçlar Tablo 9'da sunulmuştur.

Tablo 9: Model 2 Sonuçları

\begin{tabular}{|c|c|c|c|c|}
\hline \multicolumn{5}{|c|}{ Bağımlı Değişken: $\Delta F K_{t}$} \\
\hline Değişkenler & Katsayı & Robust Standart Hata & t-İstatistiği & Olasılık Değeri \\
\hline Sabit terim & 0.0005 & 0.0010 & 0.4739 & 0.6358 \\
\hline$\Delta \mathrm{FK}_{\mathrm{t}-1}$ & -0.4841 & 0.0461 & -10.496 & $0.0000^{* * *}$ \\
\hline$\Delta \mathrm{FK}_{\mathrm{t}-2}$ & -0.0987 & 0.0539 & -1.8301 & 0.0679 \\
\hline$\Delta \mathrm{FK}_{\mathrm{t}-3}$ & -0.1077 & 0.0512 & -2.1023 & $0.0361^{* *}$ \\
\hline$\Delta \mathrm{FK}_{\mathrm{t}-4}$ & 0.0407 & 0.0373 & 1.0897 & 0.2764 \\
\hline$\Delta \mathrm{FK}_{\mathrm{t}-5}$ & -0.0462 & 0.0366 & -1.2630 & 0.2072 \\
\hline$\Delta \mathrm{FM}_{\mathrm{t}}$ & 0.0726 & 0.0456 & 1.5913 & 0.1122 \\
\hline$\Delta \mathrm{FM}_{\mathrm{t}-1}$ & -0.0217 & 0.0467 & -0.4638 & 0.6430 \\
\hline$\Delta \mathrm{FM}_{\mathrm{t}-2}$ & 0.0032 & 0.0467 & 0.0688 & 0.9451 \\
\hline$\Delta \mathrm{FM}_{\mathrm{t}-3}$ & 0.0405 & 0.0458 & 0.8847 & 0.3768 \\
\hline$\Delta S 2_{t}$ & 0.1910 & 0.0518 & 3.6870 & $0.0003^{* * *}$ \\
\hline$\Delta \mathrm{S} 2_{\mathrm{t}-1}$ & 0.2884 & 0.0451 & 6.3856 & $0.0000^{* * *}$ \\
\hline$\Delta \mathrm{S} 2_{\mathrm{t}-2}$ & 0.1960 & 0.0507 & 3.8656 & $0.0001^{* * *}$ \\
\hline$\Delta \mathrm{S} 2_{\mathrm{t}-3}$ & 0.0750 & 0.0510 & 1.4694 & 0.1424 \\
\hline \multicolumn{3}{|c|}{$\mathrm{R}^{2}=0.3151$} & \multicolumn{2}{|c|}{$x^{2}=203.8386\left(0.0000^{* * *}\right)$} \\
\hline \multicolumn{2}{|c|}{$x_{F R}^{2}=24.5456\left(0.0000^{* * *}\right)$} & $x_{F M}^{2}=2.8690\left(0.0286^{* *}\right)$ & \multicolumn{2}{|c|}{$x_{s 2}^{2}=22.5203\left(0.0000^{* * *}\right)$} \\
\hline \multicolumn{5}{|c|}{$\begin{array}{l}\text { *** ve }^{* * *} \text { sirasiyla } 0.10,0.05 \text { ve } 0.01 \text { düzeyinde istatistiksel olarak anlamlılığ ifade } \\
\text { etmektedir. }\end{array}$} \\
\hline
\end{tabular}

Model 2 incelendiğinde, finansal kırılganlığın birinci gecikmeli değeri ile üçüncü gecikmeli değeri ve sermaye yeterliliğinin cari değeri, birinci ve ikinci gecikmeli değeri, finansal kırılganlığın cari değeri üzerinde anlamlı etkiye neden olmaktadır. Benzer şekilde, finansal kırılganlığın gecikmeli değerleri, sermaye yeterliliğinin cari ve gecikmeli değerleri, finansal kırılganlığın cari değeri üzerinde anlamlı bir etkiye sahiptir. Bu etki ise şu şekildedir: Finansal kırılganlığın birinci ve üçüncü gecikmeli değeri, finansal kırılganlığın cari değerini

\footnotetext{
5 White Farklı Varyans Testi'ne göre, Model 2'nin istatistik değeri 1027.44'tür. 0.01 önem düzeyinde kritik değer 27.6883 'dür. Kritik değer istatistik değerinden büyük olduğu için " $\mathrm{H}_{0}$ : Modelde farklı varyans sorunu yoktur" ifadesi reddedilmiştir.
} 
negatif yönde; sermaye yeterliliğinin cari, birinci ve ikinci gecikmeli değerleri ise pozitif yönde etkilemektedir.Faiz marjı değişkeni ele alındığında cari ve gecikmeli değerlerinin finansal kırılganlık üzerinde anlamlı bir etkisi olmadığı gözlenirken, aynı değişkenin cari ve gecikmeli değerleri birlikte ele alındığında, faiz marjının finansal kırılganlık üzerinde anlamlı bir değişime neden olduğu sonucuna ulaşılmıştır.

Çalışmada son olarak finansal kırılganlık ile yoğunlaşma arasındaki nedensel bağın varlığı ortaya konulmak istenmektedir. Bu amaçla ise Holzt-Eakin nedensellik analizinden faydalanılmış ve elde edilen sonuçlar Tablo 10'da gösterilmiştir.

Tablo 10: Holtz-Eakin Nedensellik Analizi Sonuçları

\begin{tabular}{|l|l|l|l|}
\hline $\mathbf{H}_{\mathbf{0}}$ Hipotezi & F Değeri & Olasılık Değeri & Karar \\
\hline Finansal kırılganlık, yoğunlaşmanın nedeni değildir. & 1.9636 & $0.0000^{* * *}$ & Red \\
\hline Yoğunlaşma, finansal kırılganlığın nedeni değildir. & 6.1811 & $0.0455^{* *}$ & Red \\
\hline $\begin{array}{l}\text { Gecikme uzunlukları Akaike bilgi kriterine (AIC) göre belirlenmiştir. Maksimum gecikme sayıs1 5 olarak } \\
\text { alınmıştır. }{ }^{* *} \text { ve }{ }^{* * *} \text { sirasıyla 0.10, 0.05 ve 0.01 düzeyinde istatistiksel olarak anlamlılığı ifade etmektedir. }\end{array}$ \\
\hline
\end{tabular}

Tablo 10'daki bilgilerden hareketle, finansal kırılganlığın yoğunlaşmaya neden olduğu ve yoğunlaşmanın finansal kırılganlığa neden olduğu sonucuna ulaşılmıştır. Dolayısı ile finansal kırılganlık ile yoğunlaşma arasındaki çift yönlü bir etkileşimin varlığ 0.05 önem düzeyi için geçerlidir. Finansal kırılganlık ile yoğunlaşma arasında istatistiki olarak anlamlı bir ilişkinin varlığı Pearson korelasyon matrisinden, kısa ve uzun modellerinden hareketle söylenemezken, Holtz-Eakin nedensellik analizinden hareketle finansal kırılganlıkyoğunlaşma arasında çift yönlü bir etkileşimin varlığından bahsedilebilinmektedir.

\section{SONUÇ VE DEĞERLENDİRME}

Ekonomideki en büyük finansal sektörden biri bankacılık sektörü birçok fonksiyonel işleve sahiptir. Bankacılık sektörü gerek bireyler gerekse ekonomi için önemli rollere sahiptir. $\mathrm{Bu}$ nedenle bu sektörde ortaya çıkacak kırılganlıklar ekonomik dengelerin de bozulmasına neden olacaktır. Bu noktada bankacılık sektöründe kırılganlığı etkileyen unsurların ortaya konulması önem kazanmaktadır. Literatürde bankacılık sektöründe rekabetin kırılganlık üzerindeki etkisi ile ilgili farklı görüşler bulunmaktadır. Bu görüşler "rekabet-istikrar" ve "rekabet-kırılganlık" olmak üzere ikiye ayrılmaktadır.

Çalışmada Türkiye için 2007:01-2014:09 dönemi dikkate alınmış ve bankacılık sektörüne ait değişkenler kullanılmıştır. Bu çalışmanın iki temel amacı bulunmaktadır. İlk olarak bankacılık sektöründe finansal kırılganlığı etkileyen unsurların ve "rekabet-kırılganlık" görüşünün geçerliliğinin belirlenmesi istenmektedir. $\mathrm{Bu}$ doğrultuda Pearson korelasyon matrisi analizinden yararlanılmıştır. Korelasyon analizinden elde edilen bulgulardan hareketle finansal kırılganlığın bağımlı değişken olduğu kısa ve uzun dönem modelleri oluşturulmuştur. Çalışmada, yoğunlaşmanın finansal kırılganlık üzerinden anlamlı bir etkiye sahip olmadığ 
gözlenirken, kısa dönem modelinde sermaye yeterliliğinin finansal kırılganlığ1 aynı yönde etkilediği sonucuna ulaşılmıştır. Uzun dönem modelinde ise, finansal kırılganlı̆̆ın gecikmeli değerlerinin, sermaye yeterliliğinin cari değerinin ve ilgili değişkenin gecikmeli değerlerinin finansal kırılganlığın cari değeri üzerinde istatistiki olarak anlamlı bir etkiye neden oldukları gözlenmiştir. Dolayısı ile hem kısa dönem modelinde hem de uzun dönem modelinde finansal kırılganlığı belirleyici bir unsur olarak ele alınabilecek değişkenin sermaye yeterlilik değişkeni olduğu söylenebilmektedir.

Çalışmanın son amacı ise bankacılık sektöründe meydana gelebilecek kırılganlık ile yoğunlaşma arasındaki nedensel bağın varlığının araştırılmasıdır. Bu amaç doğrultusunda ise Holtz-Eakin nedensellik analizinden faydalanılmış ve analiz sonucunda yoğunlaşmanın kırılganlığa, kırılganlığın yoğunlaşmaya neden olduğu sonucuna ulaşılmıştır. Dolayısı ile yoğunlaşmanın kırılganlığı, kırılganlığın yoğunlaşmayı tetiklediği söylenebilmektedir.

\section{KAYNAKLAR}

Abbasoğlu, O. F.- Aysan, A. F.- Gunes, A. (2007), “Concentration, Competition, Efficiency and Profitability of the Turkish Banking Sector in the Post-Crisis Period", MPRA working paper, No: 5494, pp.1-23.

Ahumadai A. C.- Budnevich, C. L. (2002), "Some Mesusures of Financial Fragility in the Chilean Banking System: An Early Warning Indicators Application", L. Hernandez and K. S. Hebbel (Eds.), Banking, Financial Integration and International Crisis. Santiago: Central Bank of Chile, pp.175-197.

Allen, F. - Gale, D. (2004), "Competition and Systemic Stability", Journal of Money, Credit and Banking, Volume 3, Issue: 36 , pp.453-480.

Altay, Oğuzhan (2014), Finansal Sistem ve Bankalar, (ss.1-13). (Editörler.) O. Altay, C. Küçüközmen, M. Ural, E. Demireli, Banka İktisadı ve İşletmeciliği Ankara: Detay Yayıncilık

Arellano, M. - O. Bover. (1995), “Another Look At The İnstrumental Variables Estimation Of Error Components Models”, Journal of Econometrics, Issue: 68, pp. 29-51.

Baltagi, Badi H. (2005). Econometric Analysis of Panel Data. John Wiley Sons .3. bask1

Barışık, Salih- Demirel, Baki (2014), "Finansal Kırılganlık ve Türk Bankacılık Sektörü İçin 2002-2011 Dönemi Finansal Kırılganlık Endeksi", TISK Akademi Sayı:16, Cilt: 9, ss.119-136

Beck, Thorsten- Demirgüç, Kunt, Asli - Levine, Ross (2006), "Bank Concentration, Competition and Crisis: First Results”. Journal of Banking and Finance, Issue: 30, Volume: 5, pp.1581-1603

Beck, Throsten (2008), “Bank Competition and Financial Stability: Friends of Foes?”, World Bank Policy Research Working Paper, No: 4656.

Berger, A.- Klapper, L.- Turk-Ariss, R. (2009), "Bank Competition and Financial Stability", Journal of Financial Services Reserch Issue: 35, Volume: 2, pp.99-118. 
Bilgin, Cevat (2007), "Finansal İstikrarsızlık Sorunu ve İktisat Politikası Bağlamında Türkiye Örneği”, Çukurova Üniversitesi Sosyal Bilimler Enstitüsü İktisat Anabilim Dalı, doktora tezi.

Boyd, J. H.- Nicolo, De- Jalal, A. M. (2006), "Bank Risk-Taking and Competition Revisited: New Theory and New Evidence", IMF Workin Paper, No: 06/297.

Boyd, John H.- Gianni, De Nicolo (2005), "The Theory of Banking Risk Taking and Competition Revisited", Journal of Finance, Issue: 60, Volume: 3, pp.1329-1343.

Breusch, T. S. - Pagan, A. R. (1980), "The Lagrange Multiplier Test and its Application to Model Specifications in Econometrics", Review of Economic Studies, Issue: 47, pp.239-253.

Carletti, Elena - Hartmann, Philipp (2002), "Competition and Financial Stability: What's Special About Banking”. European Central Bank Working Paper Series, No:146.

Cipollini, Andrea- Fiordelisi, Franco (2009), "The Impact of Bank Concentration on Financial Distress: The Case of The European Banking System", SSRN Electronic Journal DOI: $10.2139 /$ ssrn: 1343441.

Claessens, S.- Laeven, L. (2004), "What Drives Bank Competition? Some International Evidence", Journal of Mony, Credit and Banking, Issue: 36, Volume: 3, pp.563-584.

Degryse, H.- Elahi, M. A.- Penas, M. F. (2013, "Determinants of Banking System Fragility", Europen Central Bank Working Paper Series, No: 1567.

Demireli, Erhan (2010), "Finansal Kırılganlıklar: Türk Bankacıllk Sektörü Üzerine Uygulama", Elektronik Sosyal Bilimler Dergisi Sayı: 33, Cilt: 9, ss.122-140.

Emek, Uğur (2013), "Bankacıllk Sisteminde Rekabet ve İstikrar İkileminin Analizi: Türkiye Örneği”, Ankara Üniversitesi Sosyal Bilimler Enstitüsü İktisat Anabilim Dalı, Doktora tezi.

Fernandez, Raul O.- Garza-Garciab, Jesus G. (2012), "The Relationship Between Bank Competition and Financial Stability: A Case Study of the Mexican Banking Industry", Centre for Global Finance Working Paper Series, No: 03/12.

Hellmann, T. F.- Murdock, K- Stiglitz, J. (2000), “ Liberization, Moral Hazard in Banking and Prudential Regulation: Are Capital Requirements Enough?”, American Economic Review Issue: 90, Volume: 1, pp.147-16.

Holtz-Eakin, Douglas- Newey, Whitney- Rosen, Harvey S. (1988), "Estimating Vector Autoregressions with Panel Data", Econometrica, Issue: 56, Volume: 6, pp.1371-1395.

Hoyos, Rafael E. D.- Sarafidis, Vasilis (2006), "Testing for Cross-Sectional Dependence in Panel Data Models". The Stata Journal, Issue:6, Volume:4, pp.482-496.

İskenderoğlu, Ömer- Tomak, Serpil (2013). "Competition and Stability: An Analysis of the Turkish Banking System", International Journal of Economics and Financial, Issue: 3, Volume:3, pp:752-762. 
Jimenez, G.- Lopez, J.- Saurina, J. (2007), "How Does Competition Impact Bank Risk Taking?" Banco de Espana Working papers, No: 1005.

Jones, L. N.- Krause, A. S. (2007), "Latin American Banking Fragility, 1983-2002: An Assesment of the Causes and A Closer Look at the Role Played by Foreign Banks" Emory University Department of Economics Working Papers, No: 07-13.

Keeley, Micheal C. (1990), "Deposit Insurance, Risk and Market Power in Banking”, The American Economic Review, Issue: 80, Volume: 5, pp.1183-1200.

Kocabay, Selvi A. (2009), "Bank Competition and Banking System Stability: Evidence From Turkey", Middle East Technical University master thesis.

Liu, Guy -Mirzaei, Ali (2013), "Industrial Growth: Does Bank Competition, Concentration and Stability Constraint Matter? Evidence From Developed and Emerging Economics", Brunel University Economics and Finance Working Paper Series, No: 13-23.

Nicolo, Gianni D.- Lucchetta, Marcella (2011). "Bank Competition and Financial Stability: A General Equilibrium Exposition", IMF Workin Paper, No: WP/11/295.

Owen and others (2005), "Measuring Competitive Balance in Professional Team Sports Using the Herfindahl-Hirschman Index", Review of Industrial Organization, Say1: 31, Cilt: 4, pp. 289-302.

Pesola, J. (2005), "Banking Fragility and Distress: An Econometric Studuy pf Macroeconomic Determinants", Bank of Finland Research Discussion Papers, No: 132005 ,

http://www.suomenpankki.fi/en/julkaisut/tutkimukset/keskustelualoitteet/Documents/0 513netti.pdf, (10.06.2015)

Saraçoğlu, Bedriye; Kaplan, Ahmet E. (2012), "Türkiye Ekonomisinde Kırılganlıklar ve Finansal Kriz Öncü Göstergeleri”, ICIOS 2012 Eastern Meditterranean University, Department of Economics, Abstract Book, ss. 302-313

Schaeck, K.; Cihak, M.; Wolfe, S. (2006), "Are More COmpetitive Banking System More Stable?", IMF Working Paper, No: WP/06/143, https://www.imf.org/external/pubs/ft/wp/2006/wp06143.pdf, (08.05.2015)

Singh, Thangjam R. (2010), "Ordered Probit Model of Early Warning System for Predicting Financial Crisis in India”, IFC Bulletin, N0: 34, http://www.bis.org/ifc/events/5ifcconf/singh.pdf, (12.05.2015)

Stiglitz, J. Ve Weiss, A. (1981), "Credit Rationing in Markets with Imperfect Competition”. The American Economic Review, Sayı: 71, pp.393-410.

Taşkın, Dilvin (2014), “Türk Bankacılık Sektöründe Finansal İstikrar-Rekabet İlişkisi”, Maliye Finans Yazıları Sayı:103, ss.175-204 
Tunay, Batu (2009), "Türk Bankacıllk Sektöründe Rekabet ve Kırılganllk", Bankacılar Dergisi Sayi: 68, ss.30-56

Turgut, Ahmet (2007), "Türleri, Nedenleri ve Göstergeleriyle Finansal Krizler”, TÜHİS İş Hukuku ve İktisat Dergisi, Sayı:20, Cilt:5, ss.35-46

Ural, Mert (2014), "Bankacıllkta Yoğunlaşma, Rekabet ve Füzyon", O. Altay, C. Küçüközmen, M. Ural, E. Demireli (Ed.) Banka İktisadı ve İşletmeciliği (ss.397-409). Ankara: Detay Yayıncılık

Ural, Mert; Balaylar, Nilgün A. (2007), "Bankacılık Sektöründe Yüksek Risk Alımı ve Bask1 İndeksleri”, Finans Politik Ekonomik Yorumlar dergisi, Sayı:509, Cilt: 44, ss. 47-57

Yaldı, E.; Bazzana, F. (2010), "The Effect of Market Power on Bank Risk Taking in Turkey", Financial Theory and Practice Sayl: 34, Cilt: 3, pp.297-314

Yayla, M. (2007), “Türk Bankacıllk Sektöründe Yoğunlaşma ve Rekabet” BDDK Bankacılık ve Finansal Piyasalar Dergisi Sayı:1, Cilt: 1, ss.35-59. 